\title{
High or low calcium intake increases cardiovascular disease risks in older patients with type 2 diabetes
}

\author{
Jui-Hua Huang ${ }^{1}$, Leih-Ching Tsai ${ }^{2}$, Yu-Chen Chang ${ }^{1,3}$ and Fu-Chou Cheng ${ }^{4^{*}}$
}

\begin{abstract}
Background: We investigated the effects of dietary calcium (Ca) and magnesium (Mg) intakes on cardiovascular disease risks in older patients with diabetes.

Methods: In this cross-sectional study, 197 patients with type 2 diabetes aged 65 years and above were recruited. The 24-h dietary recalls and 1-week self-reported typical dietary intake patterns were collected. The Ca and Mg intakes of $<67 \%$ of the recommended dietary allowance (RDA), $67 \%-100 \%$ of RDA, and $>100 \%$ of RDA were defined as low, moderate, and high $\mathrm{Ca}$ and $\mathrm{Mg}$ intakes, respectively. Anthropometric measurements were determined and biochemical analysis of blood and urine was performed.

Results: Our data indicated that $60.9 \%$ and $87.3 \%$ of our patients were Ca and Mg intakes below RDA, respectively. Patients whose Ca intake was high or low (81.2\%) had significantly higher C-reactive protein (CRP) than those whose Ca intake was moderate $(p=0.043)$. Furthermore, patients whose Mg intake was low (87.3\%) had significantly higher CRP than that of those who took adequate Mg $(p=0.025)$. The dietary Ca:Mg intake ratios were highly correlated with CRP, platelet counts, and red blood cell distribution $(p<0.05)$. A dietary Ca:Mg intake ratio of 2.0-2.5 was significantly correlated to lower CRP levels $(p=0.013)$.

Conclusions: High or low calcium intake increases cardiovascular disease risks. We suggest that "moderate" intake of 402-600 mg Ca/day (approximately 67\%-100\% of Taiwan RDA for Ca) and adequate Mg intake (or meeting RDA for $\mathrm{Mg}$ ) with Ca:Mg intake ratio of 2.0-2.5 are important for reducing cardiovascular disease risks in older patients with diabetes.
\end{abstract}

Keywords: Calcium, Magnesium, Inflammation, Cardiovascular disease risk, Older patients with diabetes

\section{Background}

Diabetes is frequently associated with cardiovascular disease (CVD) and cardiovascular complications [1]. In general, patients with diabetes have high risk for CVD, a major death factor, particularly in older patients $[2,3]$. Inflammation also plays a key role in the pathogenesis and progression of CVD in patients with diabetes [4-6]. Diet, lifestyle, and medical interventions may promote or retard inflammatory responses in diabetic management [7-9]. Low magnesium $(\mathrm{Mg})$ and calcium $(\mathrm{Ca})$ intakes raise inflammatory and CVD risks [10-12]. However, the effects of high $\mathrm{Ca}$ or

\footnotetext{
*Correspondence: vc1035@gmail.com

${ }^{4}$ Stem Cell Center, Department of Medical Research, Taichung Veterans General Hospital, Taichung, Taiwan

Full list of author information is available at the end of the article
}

Mg intakes on cardiovascular risks in patients with diabetes remain unclear.

Low $\mathrm{Mg}$ intakes are associated with increased inflammation and risk of type 2 diabetes and CVD [12-14]. A nationally representative cross-sectional survey showed that adults in the USA consuming Mg below the recommended dietary allowances (RDAs) were more likely to have elevated C-reactive protein (CRP), which may contribute to CVD risks [12]. In rodents, the intake of an Mg-deficient high-fat diet led to alterations in the insulin-signaling pathway and increased insulin resistance [15]. In patients with diabetes, low serum Mg levels were found to be associated with macrovascular complication [16], and hypomagnesemia was arryhtmogenic [17]. In addition, low serum $\mathrm{Mg}$ levels increased chronic inflammatory stress that could be 
alleviated by increasing $\mathrm{Mg}$ intakes in middle-aged people with poor quality of sleep [18]. Dietary Ca intakes were also reported to be associated with the modulation of inflammatory stress and pathogenesis of CVD $[11,19,20]$. However, whether high $\mathrm{Ca}$ intake decreases or increases the risk of CVD remains controversial [11,20]. Zemel et al. [19] found that dietary $\mathrm{Ca}$ suppresses oxidative and inflammatory stress. A cross-sectional study showed that increased $\mathrm{Ca}$ intakes decreased the risk of several CVD risk factors [21]. In contrast, in another study, increasing dietary $\mathrm{Ca}$ intake or use of $\mathrm{Ca}$ supplementation was noted to raise myocardial infarction risks [22]. Although $\mathrm{Mg}$ and $\mathrm{Ca}$ intakes are closely related to inflammation and CVD risks, they also interact and each antagonizes the other's absorption in the intestinal tract [23]. $\mathrm{Mg}$ is a natural physiologic $\mathrm{Ca}$ antagonist. Therefore, varied $\mathrm{Mg}$ and $\mathrm{Ca}$ dietary intakes can alter the absorption of $\mathrm{Mg}$ or $\mathrm{Ca}$ alone, and inappropriate $\mathrm{Mg}$ and $\mathrm{Ca}$ dietary intakes can cause additional CVD risks.

The intestinal absorption of $\mathrm{Ca}$ or $\mathrm{Mg}$ may depend on the amounts of $\mathrm{Ca}$ and $\mathrm{Mg}$ present in the diet [23]. Therefore, owing to the nature of these intestinal interactions, the dietary Ca:Mg intake ratio and the absolute amount of $\mathrm{Ca}$ or $\mathrm{Mg}$ in the daily diet may be equally important in reducing CVD risks. Recently, Dai et al. found that the impact of Ca:Mg intake ratio on the risk of CVD had significantly higher modifying effects than that of $\mathrm{Ca}$ or $\mathrm{Mg}$ intake alone in Chinese populations [24]. In addition, the United States Department of Agriculture (USDA) food surveys from 1977 through 2008 showed a rise in the Ca:Mg intake ratio, which coincided with the increased prevalence and incidence of type 2 diabetes [25]. Therefore, the effects of dietary $\mathrm{Ca}$ and $\mathrm{Mg}$ intakes on CVD risks may vary depending on the dietary $\mathrm{Ca}: \mathrm{Mg}$ intake ratio. Thus, the roles of dietary $\mathrm{Ca}$ and $\mathrm{Mg}$ intakes and their ratio in the prevention of CVD warrant further investigation.

Older patients with diabetes are at high risk for CVD [2,3], and $\mathrm{Mg}$ deficiency is common in this population $[26,27]$. Mg deficiency may be exacerbated by low $\mathrm{Mg}$ with high or low Ca intakes [13,28], which may trigger inflammatory stress, contributing to the development of CVD [13]. However, the effects of dietary $\mathrm{Ca}$ and $\mathrm{Mg}$ intakes on CVD risk have not been intensively explored in older patients with diabetes. To date, numerous studies have demonstrated correlations between $\mathrm{Ca}$ or $\mathrm{Mg}$ intakes alone with CVD risk [10,29,30], but relatively few studies have examined the potentially combined effects of dietary intakes of $\mathrm{Ca}$ and $\mathrm{Mg}$ on CVD risk [24]. The present study was conducted to explore CVD risks in older patients with type 2 diabetes with respect to their dietary $\mathrm{Mg}$ and $\mathrm{Ca}$ intakes and Ca:Mg intake ratios. Dietary intakes and lifestyle data were obtained and assessed using questionnaires. In addition, anthropometric measurements were determined and biochemical analysis of blood and urine samples was performed.

\section{Methods}

\section{Study design}

The investigation employed a cross-sectional research design targeting patients with type 2 diabetes aged 65 years and above. Diabetes was diagnosed in the Endocrine and Metabolism Clinic according to the guidelines of the American Diabetes Association (ADA-1997) [31]. The inclusion criteria for patients were as follows: 1) type 2 diabetes for $>6$ months; 2) no change in any medications for the past 3 months; 3 ) stable lifestyle for the past 3 months; and 4) absence of heart failure, cirrhosis, current malignancy, chronic renal failure, or clinically relevant infection (CRP levels $>10 \mathrm{mg} / \mathrm{L}$ ). Patients with signs of serious deterioration in comprehension and memory were excluded. A total of 197 patients were included in the study. This investigation was performed in compliance with the Helsinki Declaration, and approved by the Changhua Christian Hospital Institutional Review Board (CCHIRB: 090419).

\section{Assessment of dietary intakes, lifestyle, and body mass index}

Dietary intakes were assessed using 24-h recall and 7-day typical dietary intake by interview and dietary records [32,33]. During the interview, quantitative tools including standard measuring spoons and cups, food models, food pictures and photos, as well as traditional household bowls, cups, and spoons were used to help the elderly subjects properly estimate their dietary intake [34]. Intakes of $\mathrm{Ca}, \mathrm{Mg}$, and other nutrients were analyzed using Taiwan's Nutrition Database and the EKitchen nutritional analysis software (Nutritional Chamberlain Line, Professional Edition, version 2001/2003, EKitchen Inc, Taichung, Taiwan) [35]. In addition, data on potential confounders, such as lifestyle factors, including physical activity, smoking, and alcohol consumption, were collected using a self-reported questionnaire. Anthropometric measurements included height and weight. Body mass index (BMI) was calculated as weight $(\mathrm{kg}) /$ height $\left(\mathrm{m}^{2}\right)$.

Moderate nutrient intakes were defined as consumption of $67 \%$ of RDA for that nutrient or $67 \%$ of its adequate intake value (AI) [36]. In the present study, assessment of $\mathrm{Ca}$ intakes was based on a previous RDA for $\mathrm{Ca}$ for Taiwanese aged 65 years and above (600 mg/day), because the $\mathrm{Ca}$ intake level for majority of older patients with diabetes was below the current AI for Ca (1000 mg/day). The $\mathrm{Ca}$ intakes were categorized as follows: 1) low: $\mathrm{Ca}$ intakes $<67 \%$ of RDA for $\mathrm{Ca}$; 2) moderate: $\mathrm{Ca}$ intakes approximately $67 \%-100 \%$ of RDA for $\mathrm{Ca}$; and 3 ) high: $\mathrm{Ca}$ intakes more than RDA for $\mathrm{Ca}$ [36]. In addition, assessment of $\mathrm{Mg}$ intakes was based on RDA for $\mathrm{Mg}$ for Taiwanese aged 65 years and above (350-360 mg/day for older men and 300-310 mg/day for older women). The Mg intakes were categorized as follows: 1) low: Mg 
intakes $<67 \%$ of RDA for $\mathrm{Mg}, 2)$ moderate: $\mathrm{Mg}$ intakes approximately $67 \%-100 \%$ of RDA for $\mathrm{Mg}$, and 3) high: $\mathrm{Mg}$ intakes more than RDA for Mg [36].

\section{Markers of inflammation and CVD risks}

Inflammatory markers were measured by the hospital medical laboratory (certified ISO15189) to assess CVD risk and included high-sensitivity CRP [37], leukocyte counts [38], platelet counts [39], and red blood cell distribution width (RDW) [40]. The high-sensitivity CRP (CV <3.0\%) was measured by particle-enhanced turbidimetric immunoassay (Dimension, Siemens, Newark, USA). The CRP levels of $<1,1-3$, and $>3 \mathrm{mg} / \mathrm{L}$ represented low, moderate, and high CVD risk, respectively [37]. Patients with clinically relevant infection (CRP levels $>10 \mathrm{mg} / \mathrm{L}$ ) were excluded. In addition, blood leukocytes $(\mathrm{CV}<3.0 \%)$ and platelets $(\mathrm{CV}<3.0 \%)$ were measured by the direct current detection method (XT1800i, Sysmex, Kobe-shi, Hyogo, Japan) and RDW was calculated. The subjects were stratified into tertiles (low, medium, and high) based on leukocyte counts, platelets, and RDW.

\section{Renal functional measurements}

The serum creatinine levels $(\mathrm{CV}<2 \%)$ were determined by the alkaline picrate-kinetic method. The estimated glomerular filtration rate (GFR) was calculated as eGFR $\left(\mathrm{mL} / \mathrm{min} / 1.73 \mathrm{~m}^{2}\right)$ (Simplified Modification of Diet in Renal Disease $($ MDRD $))=186 \times$ serum creatinine $^{-1.154} \times$ Age $^{-0.203}$ for men and $186 \times$ serum creatinine ${ }^{-1.154} \times$ Age $^{-0.203} \times$ 0.742 for women, according to the formula recommended by the Taiwan Society of Nephrology [41].

\section{Statistical analysis}

The categorical variables were analyzed by the chi-square test, and the data are presented in number (n) and percent (\%). For continuous dependent variables, comparisons of the means were analyzed by 2-tailed t-test (2 groups) or one-way ANOVA followed by Scheffe's multiple comparisons test, and the data are presented as mean $\pm \mathrm{SD}$. In addition, the correlations of dietary $\mathrm{Ca}$ and/or $\mathrm{Mg}$ intakes and markers of inflammation with CVD risks were examined by multivariate analyses, followed by Bonferroni's multiple comparisons test, and the data are presented as adjusted mean \pm standard error $(\mathrm{SE})$. All the statistical procedures were performed using SPSS 17.0 statistical software (SPSS Inc., Chicago, IL, USA), and a $p$ value $<0.05$ was considered statistically significant.

\section{Results}

The characteristics of the 197 older patients with type 2 diabetes are summarized in Table 1. Among all the patients, $60.9 \%$ of the patients' $\mathrm{Ca}$ intake was less than the previous RDA (600 mg/day) and $87.3 \%$ patients' Ca intakes were below the current AI (1000 mg/day). In addition, $87.3 \%$ of the patients' $\mathrm{Mg}$ intake was below RDA, and the total energy, carbohydrate, fat, and Mg intakes were different between men and women $(p \leqq 0.05)$. The analyses were adjusted for potential confounders, which included lifestyle factors such as physical activity, smoking, and alcohol consumption (data not shown).

As shown in Table 2, the dietary Ca:Mg intake ratio was significantly associated with the levels of CRP, platelets, and RDW $(p<0.05)$. The subgroup with a Ca:Mg intake ratio of 2.0-2.5 had significantly lower CRP and RDW than the one with a $\mathrm{Ca}: \mathrm{Mg}$ intake ratio of $>3.6$. Moreover, the subgroup with a $\mathrm{Ca}: \mathrm{Mg}$ intake ratio of 2.0-2.5 had a lower proportion of patients with $\geq 2$ high inflammatory markers, when compared with the other subgroups. However, the dietary $\mathrm{Ca}: \mathrm{Mg}$ intake ratio was not significantly associated with leukocyte count. In addition, the subgroup with a $\mathrm{Ca}: \mathrm{Mg}$ intake ratio of 2.02.5 presented a significantly higher $\mathrm{Ca}$ intake than those with $\mathrm{Ca}: \mathrm{Mg}$ intake ratios of $\leq 1.3$ and $1.4-1.9$. In contrast, the subgroup with a $\mathrm{Ca}: \mathrm{Mg}$ intake ratio of 2.0-2.5 exhibited a significantly lower $\mathrm{Ca}$ intakes than the one with a $\mathrm{Ca}: \mathrm{Mg}$ intake ratio of $>3.6$. Moreover, the dietary $\mathrm{Ca}: \mathrm{Mg}$ intake ratio showed a marginal correlation with Mg intakes $(p=0.099)$.

The relationships between CRP and dietary $\mathrm{Ca}$ or $\mathrm{Mg}$ intake alone are shown in Figure 1. Dietary $\mathrm{Ca}$ intake was significantly correlated to the CRP level $(p=0.038)$. Moreover, patients consuming moderate amount of $\mathrm{Ca}$ (402-600 $\mathrm{mg} \mathrm{Ca/day)} \mathrm{had} \mathrm{lower} \mathrm{CRP} \mathrm{than} \mathrm{those} \mathrm{con-}$ suming high amount of $\mathrm{Ca}$, i.e. $>600 \mathrm{mg} \mathrm{Ca}$ /day $(0.9 \pm$ 0.4 vs. $1.8 \pm 0.3, p=0.033)$. In addition, patients consuming high or recommended amount of $\mathrm{Mg}$ (RDA for $\mathrm{Mg}$ for healthy men and women in Taiwan above 65 years of age is $350-360$ and $300-310 \mathrm{mg} /$ day, respectively) had a lower CRP level than those consuming low amount of $\operatorname{Mg}(0.8 \pm 0.5$ vs. $1.9 \pm 0.3, p=0.012)$.

The correlations between different CRP levels (low, moderate, and high CVD risks) and different $\mathrm{Ca}$ and $\mathrm{Mg}$ intake levels (nine subgroups) were analyzed by chisquare test. The findings showed that CRP levels were correlated to dietary $\mathrm{Ca}$ and $\mathrm{Mg}$ intakes. Although some cells had an expected count of $<5$, the Chi-square test showed a statistically significant result $(p=0.001)$. The above-mentioned nine subgroups with different levels of $\mathrm{Ca}$ and $\mathrm{Mg}$ intakes were categorized as follows: 1) low $\mathrm{Ca}$ and low Mg intakes; 2) low $\mathrm{Ca}$ and moderate $\mathrm{Mg}$ intakes; 3) low $\mathrm{Ca}$ and high $\mathrm{Mg}$ intakes; 4) moderate $\mathrm{Ca}$ and low Mg intakes; 5) moderate $\mathrm{Ca}$ and moderate $\mathrm{Mg}$ intakes; 6) moderate $\mathrm{Ca}$ and high $\mathrm{Mg}$ intakes; 7) high $\mathrm{Ca}$ and low Mg intakes; 8) high $\mathrm{Ca}$ and moderate $\mathrm{Mg}$ intakes; and 9) high $\mathrm{Ca}$ and high $\mathrm{Mg}$ intakes. In addition, the correlations between different CRP levels (low, moderate, and high CVD risks) and dietary $\mathrm{Ca}: \mathrm{Mg}$ intake ratio were examined by one-way ANOVA. The results showed that the 
Table 1 Characteristics of older adults with type 2 diabetes by gender

\begin{tabular}{|c|c|c|c|c|}
\hline Variables & Total $(n=197)$ & Male $(n=90)$ & Female $(n=107)$ & $P^{4}$ \\
\hline Age (y) & $72.1 \pm 5.3$ & $72.2 \pm 5.4$ & $72.1 \pm 5.3$ & 0.935 \\
\hline \multicolumn{5}{|l|}{ Diabetes medication } \\
\hline Oral hypoglycemic drug & $138(70.1)$ & $65(72.2)$ & $73(68.2)$ & \multirow[t]{2}{*}{0.542} \\
\hline Insulin and oral hypoglycemic drug & $69(29.9)$ & 25 (27.6) & $34(31.8)$ & \\
\hline Glycated hemoglobin (\%) & $7.3 \pm 1.3$ & $7.4 \pm 1.3$ & $7.3 \pm 1.3$ & 0.534 \\
\hline Estimated GFR (ml/min) & $71.2 \pm 19.1$ & $70.3 \pm 19.1$ & $71.9 \pm 19.1$ & 0.541 \\
\hline Body mass index $\left(\mathrm{kg} / \mathrm{m}^{2}\right)$ & $25.3 \pm 3.7$ & $24.9 \pm 3.4$ & $25.6 \pm 4.0$ & 0.176 \\
\hline \multicolumn{5}{|l|}{ High-sensitivity CRP' (mg/L) } \\
\hline$<1$ low cardiovascular risk & $57(28.9)$ & $27(30.0)$ & $30(28.0)$ & \multirow[t]{3}{*}{0.169} \\
\hline 1-3 moderate cardiovascular risk & $105(53.3)$ & $52(57.8)$ & $53(49.5)$ & \\
\hline$>3$ high cardiovascular risk & $35(17.8)$ & $11(12.2)$ & $24(22.4)$ & \\
\hline \multicolumn{5}{|l|}{ Dietary intake } \\
\hline Total energy intake (kcal/day) & $1583.7 \pm 414.3$ & $1765.3 \pm 434.5$ & $1424.8 \pm 322.1$ & $<0.001$ \\
\hline Carbohydrate intake (\% of energy) & $60.9 \pm 8.5$ & $59.5 \pm 8.5$ & $62.1 \pm 8.3$ & 0.027 \\
\hline Protein intake (\% of energy) & $12.4 \pm 2.6$ & $12.5 \pm 2.4$ & $12.3 \pm 2.8$ & 0.464 \\
\hline Fat intake (\% of energy) & $26.7 \pm 7.3$ & $28.2 \pm 7.5$ & $25.3 \pm 6.9$ & 0.004 \\
\hline Calcium (mg/day) & $556.9 \pm 385.3$ & $557.9 \pm 319.1$ & $556.0 \pm 436.5$ & 0.972 \\
\hline$<\mathrm{Al}$ & $172(87.3)$ & $82(91.1)$ & $90(84.1)$ & 0.142 \\
\hline$<$ a previous $\mathrm{RDA}^{1,2}$ & $120(60.9)$ & $53(58.9)$ & $67(62.6)$ & 0.593 \\
\hline Magnesium (mg/day) & $218.4 \pm 102.4$ & $252.5 \pm 112.8$ & $188.6 \pm 81.8$ & $<0.001$ \\
\hline$<\mathrm{RDA}^{3}$ & $172(87.3)$ & $72(80.0)$ & $100(93.5)$ & 0.005 \\
\hline
\end{tabular}

${ }^{1}$ GFR: glomerular filtration rate, CRP: C-reactive protein, Al: adequate intake, RDA: recommended dietary allowance, EAR: estimated average requirement.

${ }^{2} \mathrm{~A}$ previous Taiwan RDA for Ca for healthy individuals above 65 years of age is $600 \mathrm{mg} /$ day. Current Taiwan Al of Ca for healthy individuals above 65 years of age is $1000 \mathrm{mg} /$ day.

${ }^{3}$ Taiwan RDA for Mg for health individuals above 65 years of age is 350-360 mg/day for men and 300-310 mg/day for women.

${ }^{4} \mathrm{~A} p$ value $<0.05$ was considered statistically significant. Continuous data are presented as mean \pm SD. Categorical data are presented as number ( $\mathrm{n}$ ) and percent (\%).

dietary Ca:Mg intake ratios in the low, moderate, and high CVD risk groups were $2.1 \pm 1.3,2.8 \pm 1.8$, and $3.0 \pm 1.8$, respectively $(p=0.016)$.

The distribution of patients with high CVD risk (CRP $>3 \mathrm{mg} / \mathrm{L}$ ) according to different levels of $\mathrm{Ca}$ and $\mathrm{Mg}$ intakes (nine subgroups) is presented in Figure 2. Among the patients with high CVD risk, 37.1\% had low $\mathrm{Ca}$ and low $\mathrm{Mg}$ intakes, 28.6\% had high $\mathrm{Ca}$ and low $\mathrm{Mg}$ intakes, 20.0\% had high $\mathrm{Ca}$ and moderate $\mathrm{Mg}$ intakes, and 5.7\% had low $\mathrm{Ca}$ and high $\mathrm{Mg}$ intakes. In addition, the high $\mathrm{Ca}$ and high $\mathrm{Mg}$ intakes subgroup, moderate $\mathrm{Ca}$ and moderate $\mathrm{Mg}$ intakes subgroup, and low $\mathrm{Ca}$ and moderate $\mathrm{Mg}$ intakes subgroup each comprised $2.9 \%$ of the patients with high CVD risk. No patients with high CVD risk consumed a diet with moderate amount of $\mathrm{Ca}$ and low or high amount of Mg. Furthermore, 97.1\% of the high CVD risk patients were found to consume high or low amount of $\mathrm{Ca}$ and only $2.9 \%$ consumed moderate amount of $\mathrm{Ca}$, even when these patients were stratified by $\mathrm{Mg}$ intakes. Among the high CVD risk patients who consumed low or high amount of $\mathrm{Ca}$, the percentage of patients who consumed low amount of $\mathrm{Mg}$ was higher than that of patients who consumed moderate to high amount of $\mathrm{Mg}(65.7 \%$ vs. $31.5 \%)$.

\section{Discussion}

The effects of high or low $\mathrm{Ca}$ and low $\mathrm{Mg}$ intakes on CVD risks in patients with diabetes have not been fully elucidated. This cross-sectional study investigated the effects of dietary $\mathrm{Ca}$ and $\mathrm{Mg}$ intakes on CVD risk in older patients with type 2 diabetes. Our data showed that (1) the $\mathrm{Ca}$ intake in $60.9 \%$ of the patients was lower than the previous RDA and the $\mathrm{Mg}$ intake in $87.3 \%$ of the patients was below RDA; (2) high or low Ca intake may cause high CVD risks; (3) low Mg intakes were correlated to high CVD risk; and (4) dietary Ca:Mg intake ratio of 2.0-2.5 was correlated to low CVD risks.

\section{$\mathrm{Ca}$ and $\mathrm{Mg}$ intakes in the older population}

$\mathrm{Ca}$ and $\mathrm{Mg}$ are essential elements in human physiology and are especially important in the biological functions of the cardiovascular system [30,42]. However, in many countries, it has been reported that the dietary $\mathrm{Ca}$ and $\mathrm{Mg}$ intakes in the general population remain below 
Table 2 Relationships of dietary Ca:Mg intake ratio and markers of inflammation and CVD risk in older patients with diabetes

\begin{tabular}{|c|c|c|c|c|c|c|}
\hline \multirow[b]{2}{*}{ Variables } & \multicolumn{5}{|c|}{ Quintiles of dietary Ca:Mg ratio } & \multirow[b]{2}{*}{$p^{4}$} \\
\hline & $\leq 1.3(n=40)$ & $1.4-1.9(n=39)$ & $2.0-2.5(n=42)$ & $2.6-3.6(n=38)$ & $>3.6(n=38)$ & \\
\hline \multicolumn{7}{|l|}{ Dietary $\mathrm{Ca}$ and $\mathrm{Mg}$ intake ${ }^{1}$} \\
\hline Calcium intake $(\mathrm{mg} / \text { day })^{*}$ & $212.9 \pm 179$ & $312.8 \pm 158.2$ & $555.3 \pm 219.0$ & $700.6 \pm 261.1$ & $1060 \pm 396.5$ & $<0.001$ \\
\hline Magnesium intake (mg/day) & $223.9 \pm 138.6$ & $204.3 \pm 96.9$ & $251.6 \pm 104.0$ & $231.1 \pm 90.7$ & $193.7 \pm 64.8$ & 0.099 \\
\hline \multicolumn{7}{|c|}{ Markers of inflammation and cardiovascular risk ${ }^{2}$} \\
\hline High-sensitivity CRP $(\mathrm{mg} / \mathrm{L})^{\dagger}$ & $1.8 \pm 0.3$ & $1.9 \pm 0.4$ & $1.2 \pm 0.4$ & $1.8 \pm 0.4$ & $2.7 \pm 0.4$ & 0.013 \\
\hline White blood cell $\left(10^{9}\right.$ cells $\left./ \mathrm{L}\right)$ & $6.6 \pm 0.3$ & $6.2 \pm 0.3$ & $5.9 \pm 0.3$ & $6.8 \pm 0.4$ & $6.4 \pm 0.4$ & 0.200 \\
\hline Platelet $\left(10^{3} / \mu \mathrm{L}\right)$ & $227.5 \pm 11.0$ & $203.4 \pm 11.2$ & $205.7 \pm 11.3$ & $235.5 \pm 11.7$ & $224.3 \pm 11.7$ & 0.046 \\
\hline Red blood cell distribution width (\%) ${ }^{\dagger}$ & $13.5 \pm 0.2$ & $13.6 \pm 0.2$ & $13.1 \pm 0.2$ & $13.7 \pm 0.2$ & $13.8 \pm 0.2$ & 0.032 \\
\hline \multicolumn{7}{|l|}{ Number of high inflammatory markers ${ }^{3}$} \\
\hline 0 & $10(25.0)$ & 17(43.6) & $21(50.0)$ & 12(31.6) & $7(18.4)$ & 0.002 \\
\hline 1 & 14(35.0) & $7(17.9)$ & 18(42.9) & $10(26.3)$ & $16(42.1)$ & \\
\hline$\geq 2$ & 16(40.0) & 15(38.5) & $3(7.1)$ & $16(42.1)$ & 15(39.5) & \\
\hline
\end{tabular}

${ }^{1}$ The comparisons of the means were analyzed by one-way ANOVA. *indicates significant difference in Ca intake between the subgroup with a ratio of $2.0-2.5$ and those with ratios of $\leq 1.3,1.4-1.9$, and $>3.6$ by Scheffe's multiple comparisons test

${ }^{2}$ The analyses were adjusted for sex, age, glycated hemoglobin, BMI, physical activity levels, smoking, alcohol consumption, and total energy, carbohydrate, protein, and fat intake. The data are adjusted mean \pm standard error (SE). ${ }^{\dagger}$ indicates significant difference in CRP and red blood cell distribution width between the subgroup with a ratio of $2.0-2.5$ and the one with a ratio of $>3.6$ by Bonferroni's multiple comparisons test.

${ }^{3}$ Categorical variables were analyzed by chi-square test. The data are presented as number $(\mathrm{n})$ and percent (\%). The definition of high levels of the following four inflammatory markers: CRP $>3(\mathrm{mg} / \mathrm{L})$, white blood cell $>6.5\left(10^{3} / \mathrm{mm}^{3}\right)$, platelet $>227.0\left(10^{3} / \mu \mathrm{L}\right)$, and red blood cell distribution width $>13.6(\%)$.

${ }^{4} \mathrm{~A} p$ value of $<0.05$ was considered statistically significant.

RDA, particularly among the elderly [11,43,44]. In general, RDA for Ca for healthy individuals above 65 years of age is $650-1300 \mathrm{mg} /$ day $[11,43,45]$. In our data, the daily consumption of $\mathrm{Ca}$ in older men and women with diabetes was only 558 and $556 \mathrm{mg}$, respectively. Furthermore, $60.9 \%$ of the older patients with diabetes did not meet the previous RDA for $\mathrm{Ca}(600 \mathrm{mg} /$ day), and $87.3 \%$ of the patients did not meet the current AI for $\mathrm{Ca}(1000 \mathrm{mg} /$ day). The data from the National Health and Nutrition Examination Survey (NHANES) 2005-2008 indicate that most of the Americans over 50 years of age (92-93\%) did not meet the AI for Ca (1200 mg/day) [43]. Furthermore, the data from the Nutrition and Health Surveys in Taiwan (NAHSIT) 2005-2008 show that the average Ca intakes in men and women over 50 years of age were 673 and $592 \mathrm{mg}$, respectively [46], suggesting that $82 \%-94 \%$ of Taiwanese over 65 years of age, regardless of gender, did not meet the previous RDA for Ca $(600 \mathrm{mg} /$ day) [46]. Moreover, it has been reported that dietary $\mathrm{Mg}$ intakes below RDA are common in populations throughout the world $[43,44]$. The general RDA for dietary Mg for healthy individuals above 65 years of age is $310-420 \mathrm{mg}$ /day for
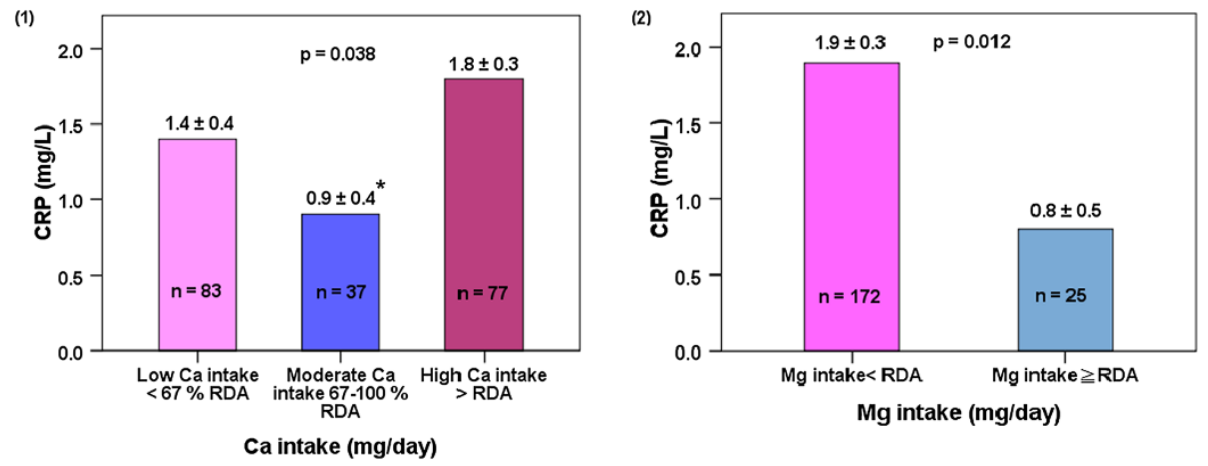

Figure 1 Relationship between CRP and Ca or Mg intake alone. (1) CRP and Ca intakes. (2) CRP and Mg intakes. The analyses were adjusted for sex, age, BMl, physical activity levels, smoking, alcohol consumption, total energy, carbohydrate, protein and fat intakes, and Mg intakes for different levels of $\mathrm{Ca}$ intakes or Ca intakes for different levels of $\mathrm{Mg}$ intakes. Data are adjusted mean \pm standard error (SE). A $p$ value of $<0.05$ was considered statistically significant. *indicates significant differences between moderate and high Ca intakes by Bonferroni's multiple comparisons test. 


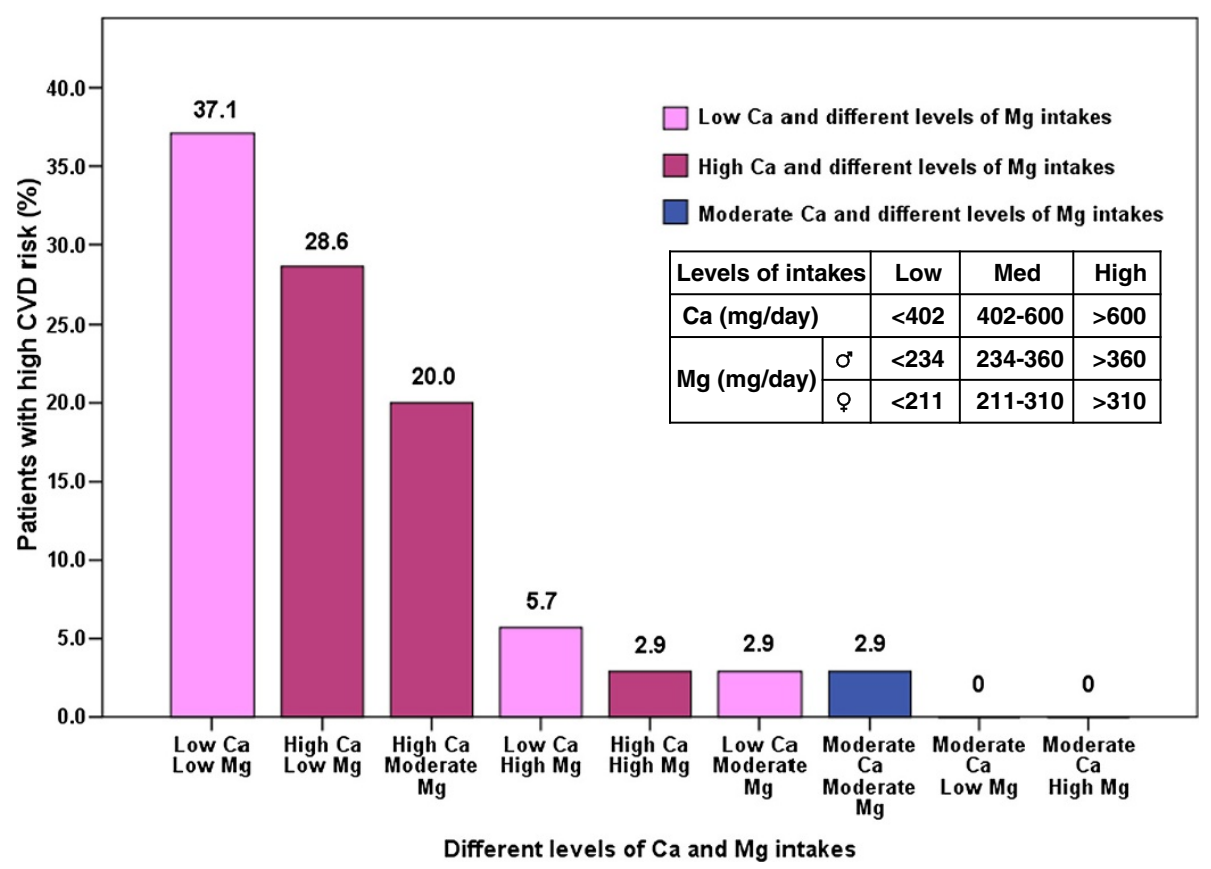

Figure 2 Distribution of high CVD risk patients according to $\mathrm{Ca}$ and $\mathbf{M g}$ intakes. CRP $>3 \mathrm{mg} / \mathrm{L}$ defined as high CVD risk. Data are presented as percent (\%).

men and 270-320 mg/day for women [43-45]. In the present study, the average $\mathrm{Mg}$ intakes in older men and women with diabetes were 253 and $189 \mathrm{mg}$, respectively. Furthermore, our data showed that the Mg intake in $80 \%$ of older men and $94 \%$ of older women with diabetes was lower than RDA. The data from the NAHSIT 2005-2008 showed that the average $\mathrm{Mg}$ intakes in men and women over 65 years were 279 and $227 \mathrm{mg}$, respectively [46]. These findings indicate that $87 \%$ of elderly men and $93 \%$ of elderly women did not meet RDA for Mg [46]. Furthermore, the data from the NHANES 2005-2008 showed that the majority of the Americans over 50 years of age $(55 \%-70 \%)$ did not meet the estimated average requirement (EAR) for $\mathrm{Mg}$ [43]. The data obtained in the present study suggest that, similar to most of the elderly people, the intakes of $\mathrm{Ca}$ and $\mathrm{Mg}$ in the majority of older patients with diabetes are low. Thus, recommendation for improvements in the dietary $\mathrm{Ca}$ and $\mathrm{Mg}$ intakes to achieve adequate intakes for the purpose of reducing CVD risks is important for older patients with diabetes.

\section{Inappropriate $\mathrm{Ca}$ intake and CVD risk}

Inappropriate $\mathrm{Ca}$ intake may be linked to triggering of an inflammatory response, which has been implicated in the pathogenesis of CVD [11]. Low Ca intake affects the development and outcome of CVD [47]. However, the effect of increased $\mathrm{Ca}$ intakes by consuming dietary $\mathrm{Ca}$ or Ca supplements on CVD risks remains controversial $[10,11,22]$. The data obtained in the present study showed that older patients with diabetes consuming diets with low level of $\mathrm{Ca}$ had higher CRP level, which may contribute to high CVD risks. Moreover, one of the major findings of the present study is that diets with high level of Ca may also cause high CVD risks unless consumed with an adequate amount of $\mathrm{Mg}$ ( $\mathrm{Mg}$ intakes $\geq$ RDA for Mg; Taiwan RDA for Mg for healthy individuals above 65 years of age is $350-360 \mathrm{mg} /$ day for men and 300-310 mg/day for women). Conversely, intake of diets with moderate amount of Ca reduces CVD risks in older patients with diabetes. Zemel et al. indicated that dietary Ca suppresses oxidative and inflammatory stress [19]. Another study demonstrated that increased Ca intakes decreased the risk of CVD [21]. In contrast, a prospective study showed that an increase in the dietary $\mathrm{Ca}$ intakes or $\mathrm{Ca}$ supplements increased myocardial infarction risk [22]. Therefore, Ca may be a double-edged sword. A deficiency of Ca may evoke increased secretion of parathyroid hormone, which increases bone resorption, thereby removing $\mathrm{Ca}$ from the bones, and excess of $\mathrm{Ca}$ is associated with many inflammatory and degenerative diseases [47]. Thus, low Ca intakes may increase CVD risks and bone loss, whereas excess $\mathrm{Ca}$ intakes may lead to $\mathrm{Ca}$ deposition in the arteries or vascular calcification, and could therefore increase the risks of CVD [11]. The findings of the present study and those from several previous studies suggest that high or low $\mathrm{Ca}$ intakes may increase the risks of CVD. Therefore, it is important to recommend a diet with moderate 
amount of $\mathrm{Ca}$ to reduce CVD risks in older patients with diabetes. It might be beneficial to suggest a range corresponding to "moderate" Ca intakes of 402-600 mg/day (approximately $67 \%-100 \%$ of Taiwan RDA for Ca).

\section{Inadequate $\mathrm{Mg}$ intake and CVD risk}

Low Mg intakes are also closely correlated to increased inflammation and CVD risks [12,13]. In the present study, patients whose Mg intake was below RDA had elevated CRP levels, which may be related to a high risk of CVD. A nationally representative cross-sectional survey showed that the $\mathrm{Mg}$ intakes in a total of $68 \%$ of the American adults were below RDA, which may result in increased CRP level and contribute to CVD risks [12]. In middle-aged people with poor quality of sleep, a low serum Mg level was reported to be correlated to increased chronic inflammatory stress that could be alleviated by increasing the $\mathrm{Mg}$ intake [18]. In the Chinese population with diabetes, patients with macrovascular complications had lower serum $\mathrm{Mg}$ level than those with no macrovascular complications [16], and hypomagnesemia was arryhtmogenic [17]. In rodents, the intake of Mg-deficient high-fat diet led to alterations in the insulin-signaling pathway and increased insulin resistance [15]. Moreover, diabetic rats showed extensive cardiac remodeling and decreased myofibrillar Ca sensitivity, consistent with the observed increases in the phosphorylation of troponin I [48]. Inadequate $\mathrm{Mg}$ intakes may cause a decrease in the extracellular $\mathrm{Mg}$, leading to the influx of $\mathrm{Ca}$ into the cells, which could trigger the release of proinflammatory cytokines and acute phase proteins from leukocytes, macrophages, and adipocytes [28,49]. Proinflammatory cytokines are released into the bloodstream and promote the release of CRP from the liver, which could result in an inflammatory response, platelet aggregation, and endothelial dysfunction, and may ultimately contribute to the development of CVD and metabolic disorder $[28,49]$. The data obtained in the present study showed that low Mg intakes are associated with high CVD risks. Thus, improvements in the dietary $\mathrm{Mg}$ intakes should be recommended for older patients with diabetes to achieve RDA for $\mathrm{Mg}$ and thereby reduce CVD risks.

\section{Dietary Ca:Mg intake ratio and CVD risk}

Systemic inflammatory activity plays a key role in the pathogenesis and progression of CVD and type 2 diabetes [4]. Inflammatory biomarkers may therefore be a valuable tool in the evaluation of CVD risk. Among the inflammatory markers, CRP is considered to be the most well-validated and standardized marker for the evaluation of CVD risks [37,50]. In addition, increased leukocyte count, platelets, and RDW are also correlated to inflammation and cardiovascular complications in patients with type 2 diabetes [38-40]. In the present study, we analyzed these inflammatory markers to determine the effects of dietary $\mathrm{Ca}$ and $\mathrm{Mg}$ intakes on CVD risks in older patients with type 2 diabetes. Our findings showed that a diet with a $\mathrm{Ca}: \mathrm{Mg}$ intake ratio of $<2.0$ or $>2.5$ may increase the risks of CVD in older patients with diabetes. In contrast, patients maintaining a dietary Ca:Mg intake ratio of 2.0-2.5 had lower levels of CRP, leukocytes, platelets, and RDW. Moreover, in the group of patients with a $\mathrm{Ca}: \mathrm{Mg}$ intake ratio of 2.0-2.5, there was a lower proportion of patients with $\geq 2$ high inflammatory markers, when compared with the other groups. These findings are in line with the recent Chinese population based cohort study [24]. Dai et al. found that the Ca:Mg intake ratio had significant modifying effects on CVD risks, when compared with the intakes of $\mathrm{Mg}$ or $\mathrm{Ca}$ alone [24]. Among the participants with Ca:Mg intake ratios $>1.7$, the intakes of $\mathrm{Ca}$ and $\mathrm{Mg}$ were associated with reduced risks of total mortality and mortality due to coronary heart diseases. Conversely, among the participants with a Ca:Mg ratio $\leq 1.7$, the intake of $\mathrm{Mg}$ was associated with increased risks of total mortality and mortality due to CVD [24]. The data from the USDA food surveys from 1977 through 2008 revealed that the dietary $\mathrm{Ca}$ intakes have increased significantly than the dietary Mg intakes. Furthermore, the Ca:Mg intake ratios were found to increase from $<2-3$ in 1995 to $\geq 3.0$ after 2000 , coinciding with a rise in the age-adjusted type 2 diabetes incidence from $3.3 \%$ to $>4.5 \%$ and age-adjusted prevalence rate increase from $4.7 \%$ to $>6.2 \%$ in the American population [25]. It has been suggested that the Ca:Mg intake ratio should not be $>2.0$ from both foods and supplements. This suggestion is consistent with one of our major findings that a dietary $\mathrm{Ca}: \mathrm{Mg}$ intake ratio of 2.0-2.5 is optimal for reducing CVD risks in older patients with diabetes. The findings of the present study and those of some previous studies indicate that a $\mathrm{Ca}: \mathrm{Mg}$ intake ratio between 1.7 and 2.5 may be required to reduce CVD risk. In general, inadequate $\mathrm{Ca}$ and/or $\mathrm{Mg}$ intakes are correlated to inflammation and CVD risk [11,28,49]. Our data suggest that dietary $\mathrm{Ca}: \mathrm{Mg}$ intake ratio is related to the markers of inflammation and cardiovascular complications in older patients with diabetes. An optimal dietary Ca:Mg intake ratio for reducing CVD risks in older diabetes patient may be $2.0-2.5$.

\section{$\mathrm{Ca}$ and $\mathrm{Mg}$ intakes and CVD risk}

$\mathrm{Ca}$ interacts and naturally antagonizes $\mathrm{Mg}$ in the absorption from the intestinal tract into the bloodstream $[23,51]$. Therefore, different dietary $\mathrm{Ca}: \mathrm{Mg}$ intake ratios alter the absorption of $\mathrm{Mg}$ or $\mathrm{Ca}$ alone, and diets with low amount of $\mathrm{Mg}$ and high or low amount of Ca may cause high CVD risk. Indeed, our data indicated that low $\mathrm{Mg}$ and high or low $\mathrm{Ca}$ intakes were more prevalent in our high CVD risk patients than moderate to high $\mathrm{Mg}$ 
and high or low Ca intakes (65.7\% vs. $31.5 \%)$. Interestingly, our data also showed that the majority of these high CVD risk patients (97.1\%) consumed high or low amount of $\mathrm{Ca}$. In contrast, the percentage of high CVD risk patients whose $\mathrm{Ca}$ intake was moderate was only $2.9 \%$. Furthermore, among the 25 patients whose Ca intakes were $>1000 \mathrm{mg} /$ day, only 4 had low CVD risks $(\mathrm{CRP}<1 \mathrm{mg} / \mathrm{L})$. Among these 4 patients, 3 consumed high amount of $\mathrm{Mg}$ and maintained a dietary $\mathrm{Ca}: \mathrm{Mg}$ intake ratio of 2.0, 2.7, and 3.3, respectively. Among the other 21 patients whose $\mathrm{Ca}$ intakes were $>1000 \mathrm{mg} /$ day and CRP $>1 \mathrm{mg} / \mathrm{L}, 5$ and 16 patients had dietary Ca:Mg intake ratios of 2.9-3.6 and $>4.7$. Moreover, our findings showed that dietary $\mathrm{Ca}: \mathrm{Mg}$ intake ratios in the low, moderate, and high CVD risk groups were $2.1 \pm 1.3,2.8 \pm$ 1.8 , and $3.0 \pm 1.8$, respectively $(p=0.016)$, indicating that inappropriate $\mathrm{Ca}$ and/or $\mathrm{Mg}$ intakes and $\mathrm{Ca}: \mathrm{Mg}$ intake ratios may increase inflammation and CVD risks. Older persons with diabetes are at high risk for CVD [2,3] and inadequate $\mathrm{Mg}$ intakes are common in older persons [27]. High or low $\mathrm{Ca}$ intake may intensify the response to subclinical Mg deficiency, leading to increased CVD risk $[13,28]$. The results obtained in the present study suggest that consumption of moderate amount of $\mathrm{Ca}$ and adequate amount of $\mathrm{Mg}$ as well as maintenance of a $\mathrm{Ca}: \mathrm{Mg}$ intake ratio of 2.0-2.5 are important for reducing CVD risks in older patients with diabetes. In addition, if patients could achieve an adequate dietary $\mathrm{Ca}$ intake of approximately $\geq 1000-1200 \mathrm{mg} /$ day by taking Ca supplements, then, to maintain a Ca:Mg intake ratio of 2.0-2.5 for reducing CVD risks, they may either have to decrease the $\mathrm{Ca}$ intake or increase the $\mathrm{Mg}$ intake.

\section{Policy implications for medical care}

Our findings raise issues that may have policy implications for medical care in older patients with diabetes. It has been established that low $\mathrm{Ca}$ and/or low $\mathrm{Mg}$ intakes could increase the risks of inflammatory responses and CVD [10-12]. As the majority of older patients with diabetes consume low amount $\mathrm{Ca}$ and $\mathrm{Mg}$, constructive strategies are needed to help these patients to achieve moderate $\mathrm{Ca}$ intake and adequate $\mathrm{Mg}$ intake through diet or supplements. Moreover, medical care practitioners should counsel patients on a more judicious dietary intake to avoid excess $\mathrm{Ca}$ consumption. In addition, the findings of the present study and those of previous studies suggest an optimal dietary $\mathrm{Ca}: \mathrm{Mg}$ intake ratio of 2.0-2.5 for reducing CVD risks. RDA was established to meet the needs of $97 \%-98 \%$ of healthy individuals. According to RDA for the elderly population above 65 years of age, the $\mathrm{Ca}: \mathrm{Mg}$ intake ratio ranges from 2.1 to 3.1 for men and from 2.4 to 4.1 for women [43-45]. Unfortunately, RDA provides an average value and does not establish the optimal balance of $\mathrm{Ca}: \mathrm{Mg}$ intake ratio. Moreover, the majority of elderly people consume inappropriate amount of $\mathrm{Ca}$ and $\mathrm{Mg}$, particularly, high amount of $\mathrm{Ca}$ and low amount of $\mathrm{Mg}$ through diet as well as $\mathrm{Ca}$ supplements, which could result in an inappropriate $\mathrm{Ca}: \mathrm{Mg}$ intake ratio of $>4$, leading to an elevated risk of CVD. Hence, further studies on the current RDA for $\mathrm{Ca}$ and $\mathrm{Mg}$ are necessary.

\section{Limitations}

While the results of the present study shed light on the effects of dietary $\mathrm{Ca}$ and $\mathrm{Mg}$ intakes on the risks of CVD in older patients with diabetes, there are several limitations to this study. First, the assessments of dietary intake and lifestyle data were highly dependent on the self-reported questionnaire. Therefore, overestimation, underestimation, or poor recall might have produced confounded results. Fortunately, these older patients with diabetes lived in rural areas, and thus, most of them had simple lifestyle and eating behaviors, which increased the effectiveness of the dietary survey. Second, the sample size was somewhat small, which may have reduced the statistical power of the subgroup analysis. Thus, to observe the effects of different dietary $\mathrm{Mg}$ and $\mathrm{Ca}$ intake levels on CVD risk, a larger sample size is required. Third, our current data showed that high or low $\mathrm{Ca}$ intake increased CVD risks, and suggested that moderate $\mathrm{Ca}$ and adequate $\mathrm{Mg}$ dietary intakes with a $\mathrm{Ca}: \mathrm{Mg}$ intake ratio of $2.0-2.5$ are important for preventing CVD in older patients with diabetes. These findings are in line with those reported by other studies $[24,25]$. The present findings may also be applicable to non-rural patient populations with type 2 diabetes and healthy adults. However, further studies are still needed to more accurately assess the role of dietary $\mathrm{Mg}$ and $\mathrm{Ca}$ intake in inflammatory response and CVD risk in other populations. In addition, further studies are required to establish whether a dietary intervention with optimal $\mathrm{Ca}$ and $\mathrm{Mg}$ intakes, as described earlier, would have a meaningful impact on CVD risks, and whether the effects of dietary $\mathrm{Mg}$ and $\mathrm{Ca}$ intakes on inflammatory stress and CVD risks could also be applied in the investigation of other diseases such as osteoporosis and cancer.

\section{Conclusions}

High or low calcium intake was found to increase CVD risks in older patients with type 2 diabetes. A balanced dietary $\mathrm{Mg}$ and $\mathrm{Ca}$ intake is highly recommended, which could be a key in reducing inflammatory responses and CVD risks. Our data suggest that (1) consuming "moderate" amount of 402-600 mg Ca/day (approximately $67 \%-100 \%$ of Taiwan RDA for Ca), (2) consuming adequate amount of $\mathrm{Mg}$ (or meeting RDA for $\mathrm{Mg}$ for healthy individuals above 65 years of age), and (3) maintaining a $\mathrm{Ca}: \mathrm{Mg}$ intake ratio of $2.0-2.5$ are important for reducing CVD risks in older patients with diabetes. 


\section{Consent}

Written informed consent was obtained from the patient for the publication of this report.

\section{Abbreviations \\ ADA: American Diabetes Association; Al: Adequate intake value; BMI: Body mass index; Ca: Calcium; CVD: Cardiovascular disease; CRP: C-reactive protein; EAR: Estimated average requirement; eGFR: Estimated glomerular filtration rate; Mg: Magnesium; MDRD: Modification of diet in renal disease: NHANES: National Health and Nutrition Examination Survey; \\ NAHSIT: Nutrition and Health Surveys in Taiwan; RDA: Recommended dietary allowance; RDW: Red blood cell distribution width.}

\section{Competing interests}

The authors declare that they have no competing interests.

\section{Authors' contributions}

$\mathrm{JHH}$ participated in the design of study, analysis, and interpretation of data, and initiated the first draft of the manuscript. LCT made substantial contributions to initiating the study and conducting the clinical study. YCC participated in the preparation of the first draft and interpretation of statistical data. FCC participated in the interpretation of the original data, and in revision and editing of the final manuscript. All the authors have read and approved the final manuscript.

\section{Acknowledgments}

This study was supported by the grant from Changhua Christian Hospital, Taiwan. The authors have no conflicts of interest. The authors thank all the patients, clinic medical staff, and Dr. Jia-zhen Lu in Changhua Christian Hospital for their enthusiastic support.

\section{Author details}

'Department of Community Health, Chia-Yi Christian Hospital, Chia-Yi, Taiwan. ${ }^{2}$ Division of Endocrine and Metabolism, Department of Internal Medicine, Erlin-Branch, Changhua Christian Hospital, Changhua, Taiwan. ${ }^{3}$ Department of Geriatric Medicine, Chia-Yi Christian Hospital, Chia-Yi, Taiwan. ${ }^{4}$ Stem Cell Center, Department of Medical Research, Taichung Veterans General Hospital, Taichung, Taiwan

Received: 14 May 2014 Accepted: 23 July 2014

Published: 1 August 2014

\section{References}

1. Huang ES, Liu JY, Moffet HH, John PM, Karter AJ: Glycemic control, complications, and death in older diabetic patients: the diabetes and aging study. Diabetes Care 2011, 34(6):1329-1336.

2. Meneilly GS, Tessier D: Diabetes in elderly adults. J Gerontol A Biol Sci Med Sci 2001, 56(1):M5-M13.

3. Booth GL, Kapral MK, Fung K, Tu JV: Relation between age and cardiovascular disease in men and women with diabetes compared with non-diabetic people: a population-based retrospective cohort study. Lancet 2006, 368(9529):29-36.

4. Willerson JT, Ridker PM: Inflammation as a cardiovascular risk factor. Circulation 2004, 109(21 Suppl 1):II2-II10.

5. Peng H, Han SH, Liu HY, Chandni V, Cai XQ, Zhang YH: Relationship of inflammation and endothelial dysfunction with risks to cardiovascular disease among people in Inner Mongolia of China. Biomed Environ Sci 2013, 26(10):792-800.

6. Ridker PM, Buring JE, Cook NR, Rifai N: C-reactive protein, the metabolic syndrome, and risk of incident cardiovascular events: an 8-year follow-up of 14719 initially healthy American women. Circulation 2003, 107(3):391-397.

7. Nanri A, Moore MA, Kono S: Impact of C-reactive protein on disease risk and its relation to dietary factors. Asian Pac J Cancer Prev 2007, 8(2):167-177.

8. Iso H: Lifestyle and cardiovascular disease in Japan. J Atheroscler Thromb 2011, 18(2):83-88.

9. Buse JB, Ginsberg HN, Bakris GL, Clark NG, Costa F, Eckel R, Fonseca V, Gerstein HC, Grundy S, Nesto RW, Pignone MP, Plutzky J, Porte D, Redberg R, Stitzel KF, Stone NJ: Primary prevention of cardiovascular diseases in people with diabetes mellitus: a scientific statement from the American heart association and the American diabetes association. Diabetes Care 2007, 30(1):162-172.

10. Wang L, Manson JE, Sesso HD: Calcium intake and risk of cardiovascular disease: a review of prospective studies and randomized clinical trials. Am J Cardiovasc Drugs 2012, 12(2):105-116.

11. Peterlik M, Kallay E, Cross HS: Calcium nutrition and extracellular calcium sensing: relevance for the pathogenesis of osteoporosis, cancer and cardiovascular diseases. Nutrients 2013, 5(1):302-327.

12. King DE, Mainous AG 3rd, Geesey ME, Woolson RF: Dietary magnesium and C-reactive protein levels. J Am Coll Nutr 2005, 24(3):166-171.

13. Nielsen FH: Magnesium, inflammation, and obesity in chronic disease. Nutr Rev 2010, 68(6):333-340.

14. Rodriguez-Moran M, Simental Mendia LE, Zambrano Galvan G, GuerreroRomero F: The role of magnesium in type 2 diabetes: a brief basedclinical review. Magnes Res 2011, 24(4):156-162.

15. Sales CH, Santos AR, Cintra DE, Colli C: Magnesium-deficient high-fat diet: effects on adiposity, lipid profile and insulin sensitivity in growing rats. Clin Nutr 2014, (In Press, Available online 16 October 2013; doi:10.1016/j. clnu.2013.10.004).

16. Wang S, Hou X, Liu Y, Lu H, Wei L, Bao Y, Jia W: Serum electrolyte levels in relation to macrovascular complications in Chinese patients with diabetes mellitus. Cardiovasc Diabetol 2013, 12:146.

17. Del Gobbo LC, Song Y, Poirier P, Dewailly E, Elin RJ, Egeland GM: Low serum magnesium concentrations are associated with a high prevalence of premature ventricular complexes in obese adults with type 2 diabetes. Cardiovasc Diabetol 2012, 11:23.

18. Nielsen FH, Johnson LK, Zeng H: Magnesium supplementation improves indicators of low magnesium status and inflammatory stress in adults older than 51 years with poor quality sleep. Magnes Res 2010, 23(4):158-168.

19. Zemel MB, Sun $X$ : Dietary calcium and dairy products modulate oxidative and inflammatory stress in mice and humans. J Nutr 2008, 138(6):1047-1052.

20. Peterlik M, Cross HS: Vitamin D and calcium insufficiency-related chronic diseases: molecular and cellular pathophysiology. Eur J Clin Nutr 2009, 63(12):1377-1386.

21. da Silva FT, Torres MR, Sanjuliani AF: Dietary calcium intake is associated with adiposity, metabolic profile, inflammatory state and blood pressure, but not with erythrocyte intracellular calcium and endothelial function in healthy pre-menopausal women. Br J Nutr 2013, 110(6):1079-1088.

22. Li K, Kaaks R, Linseisen J, Rohrmann S: Associations of dietary calcium intake and calcium supplementation with myocardial infarction and stroke risk and overall cardiovascular mortality in the Heidelberg cohort of the European Prospective Investigation into Cancer and Nutrition study (EPIC-Heidelberg). Heart 2012, 98(12):920-925.

23. Hardwick LL, Jones MR, Brautbar N, Lee DB: Magnesium absorption: mechanisms and the influence of vitamin D, calcium and phosphate. J Nutr 1991, 121(1):13-23.

24. Dai Q, Shu XO, Deng X, Xiang YB, Li H, Yang G, Shrubsole MJ, Ji B, Cai H, Chow WH, Yu-Tang G, Wei Z: Modifying effect of calcium/magnesium intake ratio and mortality: a population-based cohort study. BMJ Open 2013, 3(2):e002111.

25. Rosanoff A: Rising Ca: Mg intake ratio from food in USA Adults: a concern? Magnes Res 2010, 23(4):S181-S193.

26. Barbagallo M, Di Bella G, Brucato V, D'Angelo D, Damiani P, Monteverde A, Belvedere M, Dominguez $L J$ : Serum ionized magnesium in diabetic older persons. Metabolism 2014, 63(4):502-509.

27. Barbagallo M, Dominguez $\amalg$ : Magnesium and aging. Curr Pharm Des 2010, 16(7):832-839.

28. Mazur A, Maier JA, Rock E, Gueux E, Nowacki W, Rayssiguier Y: Magnesium and the inflammatory response: potential physiopathological implications. Arch Biochem Biophys 2007, 458(1):48-56.

29. Chacko SA, Song $Y$, Nathan $L$, Tinker $L$, de Boer $\|_{\text {, }}$, Tylavsky F, Wallace $R$, Liu S: Relations of dietary magnesium intake to biomarkers of inflammation and endothelial dysfunction in an ethnically diverse cohort of postmenopausal women. Diabetes Care 2010, 33(2):304-310.

30. Xiao Q, Murphy RA, Houston DK, Harris TB, Chow WH, Park Y: Dietary and supplemental calcium intake and cardiovascular disease mortality: the National Institutes of Health-AARP diet and health study. JAMA Intern Med 2013, 173(8):639-646.

31. American Diabetes Association: Report of the expert committee on the diagnosis and classification of diabetes mellitus. Diabetes Care 1997, 20:1183-1197. 
32. Thompson FE, Byers T: Dietary assessment resource manual. J Nutr 1994, 124(11 Suppl):2245S-2317S

33. Xu J, Eilat-Adar S, Loria CM, Howard BV, Fabsitz RR, Begum M, Zephier EM, Lee ET: Macronutrient intake and glycemic control in a population-based sample of American Indians with diabetes: the strong heart study. Am J Clin Nutr 2007, 86(2):480-487.

34. Posner BM, Smigelski C, Duggal A, Morgan JL, Cobb J, Cupples LA: Validation of two-dimensional models for estimation of portion size in nutrition research. J Am Diet Assoc 1992, 92(6):738-741.

35. Huang MC, Hsu CC, Wang HS, Shin SJ: Prospective randomized controlled trial to evaluate effectiveness of registered dietitian-led diabetes management on glycemic and diet control in a primary care setting in Taiwan. Diabetes Care 2010, 33(2):233-239.

36. Marshall TA, Stumbo PJ, Warren JJ, Xie XJ: Inadequate nutrient intakes are common and are associated with low diet variety in rural community-dwelling elderly. J Nutr 2001, 131(8):2192-2196.

37. Pearson TA, Mensah GA, Alexander RW, Anderson JL, Cannon RO 3rd, Criqui M, Fadl YY, Fortmann SP, Hong Y, Myers GL, Rifai N, Smith SC Jr, Taubert K, Tracy RP, Vinicor F, Centers for Disease Control and Prevention; American Heart Association: Markers of inflammation and cardiovascular disease: application to clinical and public health practice: a statement for healthcare professionals from the centers for disease control and prevention and the American heart association. Circulation 2003 107(3):499-511.

38. Peter C, Tong K-FL, Wing-Yee S, Margaret HN, Wing-Bun C, Lo MK, Chan NN Chan JC: White blood cell count is associated with macro- and microvascular complications in Chinese patients with type 2 diabetes. Diabetes Care 2004, 27:216-222

39. Rondina MT, Wevrich AS, Zimmerman GA: Platelets as cellular effectors of inflammation in vascular diseases. Circ Res 2013, 112:1506-1519.

40. Sherif H, Ramadan N, Radwan M, Hamdy E, Reda R: Red cell distribution width as a marker of inflammation in type 2 diabetes mellitus. Life Sci J 2013, 10(3):1501-1507.

41. Matsuo S, Yasuda Y, Imai E, Horio M: Current status of estimated glomerular filtration rate (eGFR) equations for Asians and an approach to create a common eGFR equation. Nephrology (Carlton) 2010, 15(Suppl 2):45-48.

42. Qu $X$, Jin F, Hao $Y$, Li H, Tang T, Wang H, Yan W, Dai K: Magnesium and the risk of cardiovascular events: a meta-analysis of prospective cohort studies. PLoS One 2013, 8(3):e57720.

43. Moshfegh AJ, Goldman JD, Ahuja JK, Rhodes DG, LaComb RP: What We Eat in America, NHANES 2005-2006: Usual Nutrient Intakes from Food and Water Compared to 1997 Dietary Reference Intakes for Vitamin D, Calcium, Phosphorus, and Magnesium (24-Page Report). US Department of Agriculture. Agricultural Research Service; 2009. http://www.ars.usda.gov/SP2UserFiles/ Place/12355000/pdf/0506/usual_nutrient_intake_vitD_ca_phos_mg_200506.pdf (accessed 28 July 2014).

44. Wang JL, Weng YL, Pan WH, Kao MD: Trends and nutritional status for magnesium in Taiwan from NAHSIT 1993 to 2008. Asia Pac J Clin Nutr 2011, 20(2):266-274.

45. Sasaki S: Dietary reference intakes (DRIs) in Japan. Asia Pac J Clin Nutr 2008, 17(Suppl 2):420-444.

46. Wu SJ, Pan WH, Yeh NH, Chang HY: Trends in nutrient and dietary intake among adults and the elderly: from NAHSIT 1993-1996 to 2005-2008. Asia Pac J Clin Nutr 2011, 20(2):251-265.

47. Heaney RP: Low calcium intake among African Americans: effects on bones and body weight. J Nutr 2006, 136(4):1095-1098.

48. Zhang L, Ward ML, Phillips AR, Zhang S, Kennedy J, Barry B, Cannell MB, Cooper GJ: Protection of the heart by treatment with a divalent-copperselective chelator reveals a novel mechanism underlying cardiomyopathy in diabetic rats. Cardiovasc Diabetol 2013, 12:123.

49. Rayssiguier Y, Libako P, Nowacki W, Rock E: Magnesium deficiency and metabolic syndrome: stress and inflammation may reflect calcium activation. Magnes Res 2010, 23(2):73-80.
50. Lowe G, Woodward M, Hillis G, Rumley A, Li Q, Harrap S, Marre M, Hamet P, Patel A, Poulter N, Chalmers J: Circulating inflammatory markers and the risk of vascular complications and mortality in people with type 2 diabetes and cardiovascular disease or risk factors: the ADVANCE study. Diabetes 2014, 63(3):1115-1123

51. Uzui H, Lee JD: Role of magnesium in hypertension therapy. Clin Calcium 2005, 15(11):117-122.

doi:10.1186/s12933-014-0120-0

Cite this article as: Huang et al:: High or low calcium intake increases cardiovascular disease risks in older patients with type 2 diabetes.

Cardiovascular Diabetology 2014 13:120.

\section{Submit your next manuscript to BioMed Central and take full advantage of:}

- Convenient online submission

- Thorough peer review

- No space constraints or color figure charges

- Immediate publication on acceptance

- Inclusion in PubMed, CAS, Scopus and Google Scholar

- Research which is freely available for redistribution

Submit your manuscript at www.biomedcentral.com/submit
C Biomed Central 